\title{
14 State of the Art and Progress in the Earthquake Early Warning System in Taiwan
}

\author{
Yih-Min $\mathrm{Wu}^{1}$, Nai-Chi Hsiao ${ }^{2}$, William H.K. Lee ${ }^{3}$, Ta-liang Teng ${ }^{4}$, \\ Tzay-Chyn Shin $^{2}$ \\ ${ }^{1}$ Department of Geosciences, National Taiwan University, Taipei, Taiwan \\ ${ }^{2}$ Central Weather Bureau, Taipei, Taiwan \\ ${ }^{3}$ U. S. Geological Survey (retired), Menlo Park, California, USA \\ ${ }^{4}$ Southern California Earthquake Center, University of Southern \\ California, Los Angeles, California, USA
}

\begin{abstract}
We report here the recent progress and future development of real-time seismic monitoring in Taiwan, especially on earthquake early warning system (EWS) developed at the Central Weather Bureau (CWB), using the telemetered signals from strong-motion instruments. Utilizing a quick magnitude determination based on the first $10 \mathrm{sec}$ of signals from a virtual and sub-network which is configured automatically, we were able to reduce the earthquake rapid reporting time to about $30 \mathrm{sec}$ or less. This represents a significant step towards a more realistic earthquake early warning capability. This early warning system has been in operation at CWB since 2002. Comprehensive earthquake reports have been issued mostly in less than $30 \mathrm{sec}$, with an average of about $22 \mathrm{sec}$ from the origin time. At $3 \mathrm{~km} / \mathrm{sec}$ for a typical crustal shear-wave velocity, the present operation is not useful if an earthquake occurs less than about $70 \mathrm{~km}$ from a city, but the lead time will increase to more than $10 \mathrm{sec}$ for cities at distances greater than $100 \mathrm{~km}$ from the earthquake source. In the latter case, a lead time of several seconds will allow pre-programmed emergency response to take place prior to the arrival of strong ground shaking. In order to offer earlier warning within an epicentral distance of less than $70 \mathrm{~km}$, a $\tau_{\mathrm{c}}$ and Pd method was experimented. We used the Taiwan Strong-Motion Instrumentation Program (TSMIP) accelerograms recorded within epicentral distances of less than $30 \mathrm{~km}$ from $\mathrm{Mw}>5.0$ crustal earthquakes. This method uses the first 3-sec length records from the onset of P-waves and could issue an on-site early warning within $10 \mathrm{sec}$ after the event origin
\end{abstract}


time, reducing the radius of the blind zone from 70 to $25 \mathrm{~km}$ from the epicenter.

\subsection{Introduction}

Located on the western circum-Pacific seismic belt with a plate convergence rate of $8 \mathrm{~cm} /$ year (Yu et al. 1999), Taiwan has experienced many destructive earthquakes with severe casualties and property losses. For examples, on March 17, 1906 a damaging earthquake $(M=7.1)$ occurred in Chiayi (Hsu 2003), in 1935, a disastrous earthquake $(M=7.1)$ in the Hsinchu-Taichung area (Hsu 2003), and the 1999 Chi-Chi earthquake (Mw $=7.6$ ) occurred in Nantou County (Teng et al. 2001, Shin and Teng 2001). The potential earthquake hazard will continue to increase along with population growth. Therefore, it is essential for Taiwan to seek means through scientific research to reduce future earthquake hazards.

Due to the extreme complexity involved in the earthquake processes, reliable earthquake prediction is not currently possible (Kanamori 2003). Present technological advances in seismic instrumentation and in digital communication and processing permit implementation of a real-time earthquake monitoring system (Lee 1995). In terms of seismic hazards mitigation, an early warning system (EWS) is a practical and promising tool to reduce loss caused by a damaging earthquake (Nakamura 1988, Espinosa-Aranda et al. 1995, Lee et al. 1996, Kanamori et al. 1997, Teng et al. 1997, United States Geological Survey 1998, Wu et al. 1998, Wu and Teng 2002, Allen and Kanamori 2003, Lee and Espinosa-Aranda 2003).

The main purpose of this paper is to summarize the state of the art and progress in the earthquake early warning system in Taiwan. In a recent workshop on earthquake warning systems held on July 13-15, 2005 at the California Institute of Technology, Pasadena, Teng et al. (2005) summarized the development of earthquake rapid reporting and early warning systems in Taiwan; Hsiao et al. (2005) presented the current status of earthquake rapid reporting and early warning systems at the Central Weather Bureau (CWB) in Taiwan; and Lee et al. (2005) proposed a plan to the CWB to integrate tsunami warning with earthquake rapid reporting and early warning. 


\subsection{Physical Basis for Earthquake Early Warning and its Benefits}

The physical basis for an earthquake early warning system is simple: (1) strong ground shaking from a damaging earthquake is caused by shear (S) waves and the following surface waves, (2) typical crustal P-wave velocity is about $6-8 \mathrm{~km} / \mathrm{sec}$, whereas $\mathrm{S}$ - and surface waves travel at about half the speed of the P-waves, and (3) the seismic wave velocities are much slower than electromagnetic signals transmitted by telegraph, telephone, or radio at about $300,000 \mathrm{~km} / \mathrm{sec}$.

Cooper (1868) was the first to propose an earthquake early warning system more than one hundred years ago. In the mid-nineteenth century, there were frequent earthquakes near Hollister, California, about $120 \mathrm{~km}$ southeast of San Francisco. Cooper proposed setting up seismic detectors near Hollister and when an earthquake triggered them, an electric signal would be sent by telegraph to San Francisco. This signal would then ring a big bell in the City Hall to warn citizens that an earthquake had occurred. Unfortunately, Cooper's scheme was never implemented. More than 100 years later, Heaton (1985) proposed a seismic computerized alert network for southern California. Nakamura (1988) implemented the single-station urgent earthquake detection and alarm system (UrEDAS) for the "bullet" train system in Japan. Espinosa-Aranda et al. (1995) established the first earthquake early warning system for large events in the Oaxaca coastal region several hundred km away; the system should broadcast to the public in the Mexico City. Subsequently, earthquake early warning systems have been implemented, experimented, and commented upon by several different groups as reported in Chapters 5.2 to 5.14 in Zschau and Kuppers (2003). More recently, an international workshop on earthquake early warning was held on July 13-15, 2005 at the California Institute of Technology, Pasadena (website address: http://www.seismolab.caltech.edu/early.html).

An EWS forewarns an urban area of forthcoming strong shaking, normally with a few seconds to a few tens of seconds of early warning time, i.e., before the arrival of the destructive S- and surface waves of a damaging earthquake. Even a few seconds of advanced warning time will be useful for pre-programmed emergency measures for various critical facilities, such as the deceleration of rapid-transit vehicles and high-speed trains to avoid potential derailment, the orderly shutoff of gas pipelines to minimize fire hazards, the controlled shutdown of high-technological manufacturing operations to reduce potential losses, and the safe-guarding of computer facilities to avoid the loss of vital data. 


\subsection{Progress in Earthquake Early Warning in Taiwan}

Progress has been made towards earthquake early warning, for example, in Japan, Mexico, and Taiwan (see e.g., Nakamura 1988, Espinosa-Aranda et al. 1995, Lee et al. 1996, Wu and Teng 2002). Two approaches have been tried: (1) using an array of seismic stations for regional warning, and (2) using a single seismic station for individual onsite warning. In (1), there are two variants: (a) detect an earthquake and decide if it is "large" enough to issue a warning message to the public, and (b) detect and locate an earthquake, and estimate its magnitude and the expected ground motions in the monitored region, then issue a more informative warning message to the public. In (2), the beginning of the ground motion (mainly P-waves) observed at a site is used to predict the ensuing ground motion (mainly by $\mathrm{S}$ - and surface waves) at the same site; either an attempt is made for a single-station event location and magnitude estimation, or no attempt is made to locate the event and estimate the magnitude. The first approach is more comprehensive, but takes a longer time and cannot be used for early warning purposes at short epicentral distances. It has been used, for example, in Mexico and Taiwan. In contrast, the second approach is very fast, can provide useful early warning to sites even at very short epicentral distances where an early warning is most needed, and has been used, for example, in Japan and United States.

The approach of the EWS in Taiwan was motivated by the experience of the 15 November, 1986 Hualien, Taiwan, earthquake of $\mathrm{M}_{\mathrm{L}} 6.8$ (or $\mathrm{M}_{\mathrm{W}}$ 7.3). Although the epicenter of that earthquake was located near Hualien, the most severe damage occurred in the Taipei metropolitan area, about $120 \mathrm{~km}$ away (Fig. 14.1). According to the travel times of past earthquakes in Taiwan, shear waves traveling over this distance should take more than $30 \mathrm{sec}$. Thus, if a seismic monitoring system can reliably estimate the location and magnitude within $30 \mathrm{sec}$ of a large earthquake that could threaten a metropolitan area, then several or more seconds of advanced warning will be available for emergency response.

A continuous telemetered strong-motion network was installed in Taiwan, and a Rapid Earthquake Information Release System (RTD) was implemented by the CWB for monitoring earthquakes in real time since 1995 (Wu et al. 1997). In order to maximize the use of the data from this network, the CWB utilized its RTD system as a basis for the development of EWS capabilities.

This RTD system uses a real-time strong-motion accelerograph network that currently consists of 97 telemetered strong-motion stations distributed over Taiwan (Fig. 14.1), an area of $100 \mathrm{~km}$ x $300 \mathrm{~km}$. Each station has 3- 
component force-balanced accelerometers with signals being digitized continuously at 200 samples per sec per channel at 16-bit resolution, but telemetered at 50 samples per sec per channel using 4800-baud telemetry. The full recording dynamic range is $\pm 2 \mathrm{~g}$, and has a sensitivity sufficient to record $\mathrm{M}>4.0$ events at distances of $100 \mathrm{~km}$ or more. Currently, RTD system can offer useful information about one minute after an earthquake occurs (Teng et al. 1997, Wu et al. 1997). Information includes earthquake location, its magnitude, and a shake map of Taiwan. Rapid damage assessment can also be determined and issued by the RTD system a minute or so later (Wu et al. 2002). By applying the sub-network approach (Wu et al. 1999, Wu and Teng 2002) and the $\mathrm{M}_{\mathrm{L} 10}$ method (Wu et al. 1998), the RTD system can achieve an earthquake reporting time of about $20 \mathrm{sec}$. Therefore, it can offer earthquake early warning for metropolitan areas located at $70 \mathrm{~km}$ from the epicenter and beyond.

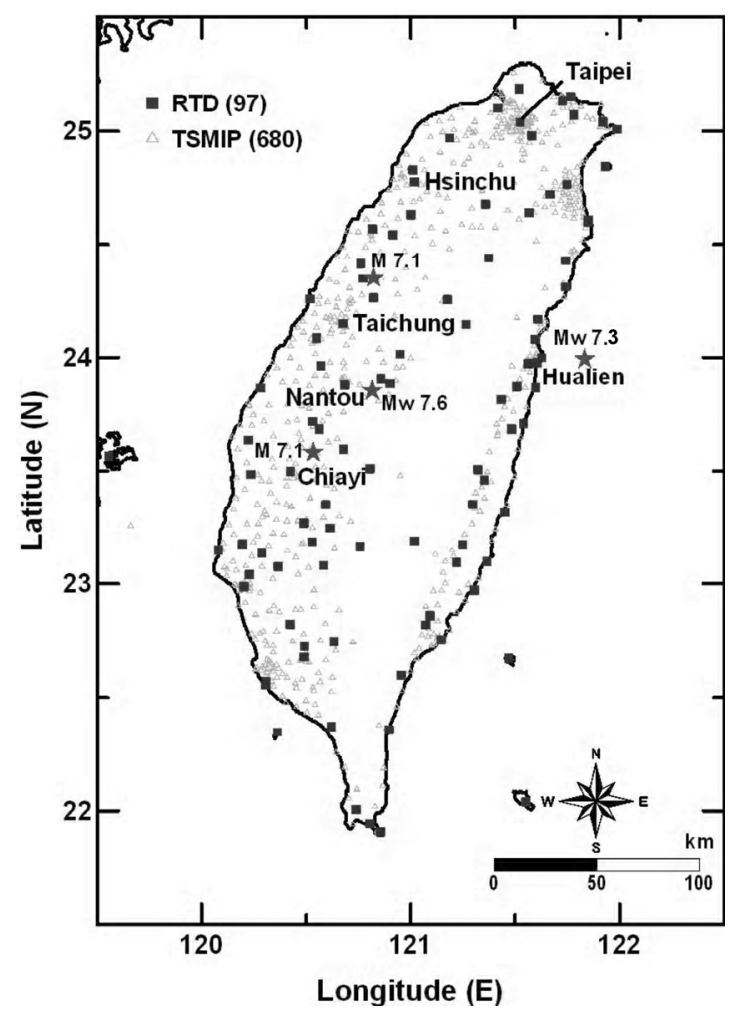

Fig. 14.1 Distribution of the 97 real-time and 680 free-field strong-motion stations in Taiwan. 
The RTD system is a typical regional warning system for EWS. Recently, onsite EWS methods were also experimented in Taiwan (Wu and Kanamori 2005a, 2005b). It is possible to shorten the reporting time to about $10 \mathrm{sec}$. Therefore, this onsite method will play an important role for the future development of EWS in Taiwan.

\subsection{Current Regional Warning System}

The RTD system can routinely broadcast the location and magnitude of a strong earthquake as well as the intensity distribution in about $60 \mathrm{sec}$ after the origin time of the earthquake. However, the 60-sec time lapse is too long to be practical for earthquake early warning purposes. Therefore, shortening of the reporting time of the RTD system is required in order to achieve early warning functions. Many studies include rapid event location, magnitude determination, sub-network, and virtual sub-network approaches were developed by the CWB in recent years (Lee et al. 1996, Wu et al. 1998, 1999, Wu and Teng 2002).

\subsubsection{Rapid Local Magnitude Determination - $\mathrm{M}_{\mathrm{L} 10}$ Method}

Two major requirements for an earthquake early warning system are the near real-time estimation of the earthquake location and of its magnitude. The first requirement on rapid location can be achieved readily in the 10sec time window immediately following the first P-arrival. On the other hand, the second requirement of rapid determination of earthquake magnitude would be more difficult because the shear-wave trains may not be recorded completely within this time window, and, more importantly, since a moment magnitude $\left(\mathrm{M}_{\mathrm{w}}\right)$ or its equivalence must be developed for large earthquakes. Thus, a method for quick $\mathrm{M}_{\mathrm{w}}$ magnitude determination for large events needs to be developed. Although many researchers (e.g., Nakamura 1988, Grecksch and Kumpel 1997, Allen and Kanamori 2003, Kanamori 2005, Wu and Kanamori 2005a, Wu et al. 2006a, 2006b, Wu and Zhao 2006) have also tried to estimate magnitude from the initial portion of the seismograms, large uncertainties in magnitude are inevitable in these methods. Based on the current configuration of the RTD system and its monitoring area, we developed an empirical method to reliably determine earthquake magnitude within $20 \mathrm{sec}$ after the first P-wave arrives at the nearest stations.

Twenty-three sets of strong-motion data from moderate earthquakes $\left(\mathrm{M}_{\mathrm{L}}\right.$ $>$ 5.0) in the Taiwan area are used to achieve this goal. For earthquakes 
larger than $\mathrm{M}_{\mathrm{L}} 5$, epicenters can be reliably determined in about $15 \mathrm{sec}$ after the arrival of the P-waves from the nearest stations. Figure 14.2 shows simulated Wood-Anderson seismograms from the 25 June, 1995 earthquake $\left(M_{L} 6.5\right)$. In the first $10 \mathrm{sec}$, there are seven $P$ phases and two $S$ phases that can be used to locate the earthquake. The earthquake magnitude $\mathrm{M}_{\mathrm{L}}$ cannot be determined in the same time frame due to the incomplete recording of shear waves at some stations. However, the magnitude based on the first $10 \mathrm{sec}$ of the signals $\left(\mathrm{M}_{\mathrm{L} 10}\right)$ can be found to correlate with $\mathrm{M}_{\mathrm{L}}$ (Fig. 14.3) as follows:

$$
M_{L}=1.28 * M_{L 10}-0.85 \pm 0.13 .
$$

By applying this method for magnitude determination, the CWB system can determine hypocenter and magnitude with tolerable uncertainty in about $30 \mathrm{sec}$ after the occurrence of an earthquake, and early warning is thus possible in Taiwan.

\subsubsection{Sub-network Approach}

In order to explore the feasibility of an earthquake early warning system for Taipei, a prototype early warning system was implemented in Hualien about $120 \mathrm{~km}$ away. Through previous studies (Wu et al. 1997), we concluded that using a dense sub-network under the RTD system is a good approach to shorten the reporting time, and thus gaining some earthquake early warning capabilities. Thus, a dense, real-time monitoring system with high-density station coverage in the Hualien area, and lesser density outside the Hualien area (Fig. 14.4) was developed for testing early warning capability from earthquake sources in the Hualien area. The highdensity station coverage in the Hualien area was designed for recording shear waves to enhance magnitude determination, and the stations outside the Hualien area were designed to provide more P-arrivals to improve location quality.

For the 43 earthquakes with $\mathrm{M}_{\mathrm{L}}>4.5$ that occurred from August 1998 to June 2005, this system successfully reported earthquake information in about $19 \mathrm{sec}$ (Fig. 14.5) after the origin time with the location uncertainty under $10 \mathrm{~km}$ and the magnitude uncertainty below 0.3 . Therefore, it provides about $15 \mathrm{sec}$ of early warning time before shear-waves arrive in the Taipei urban area for earthquakes occurring in the Hualien area. 


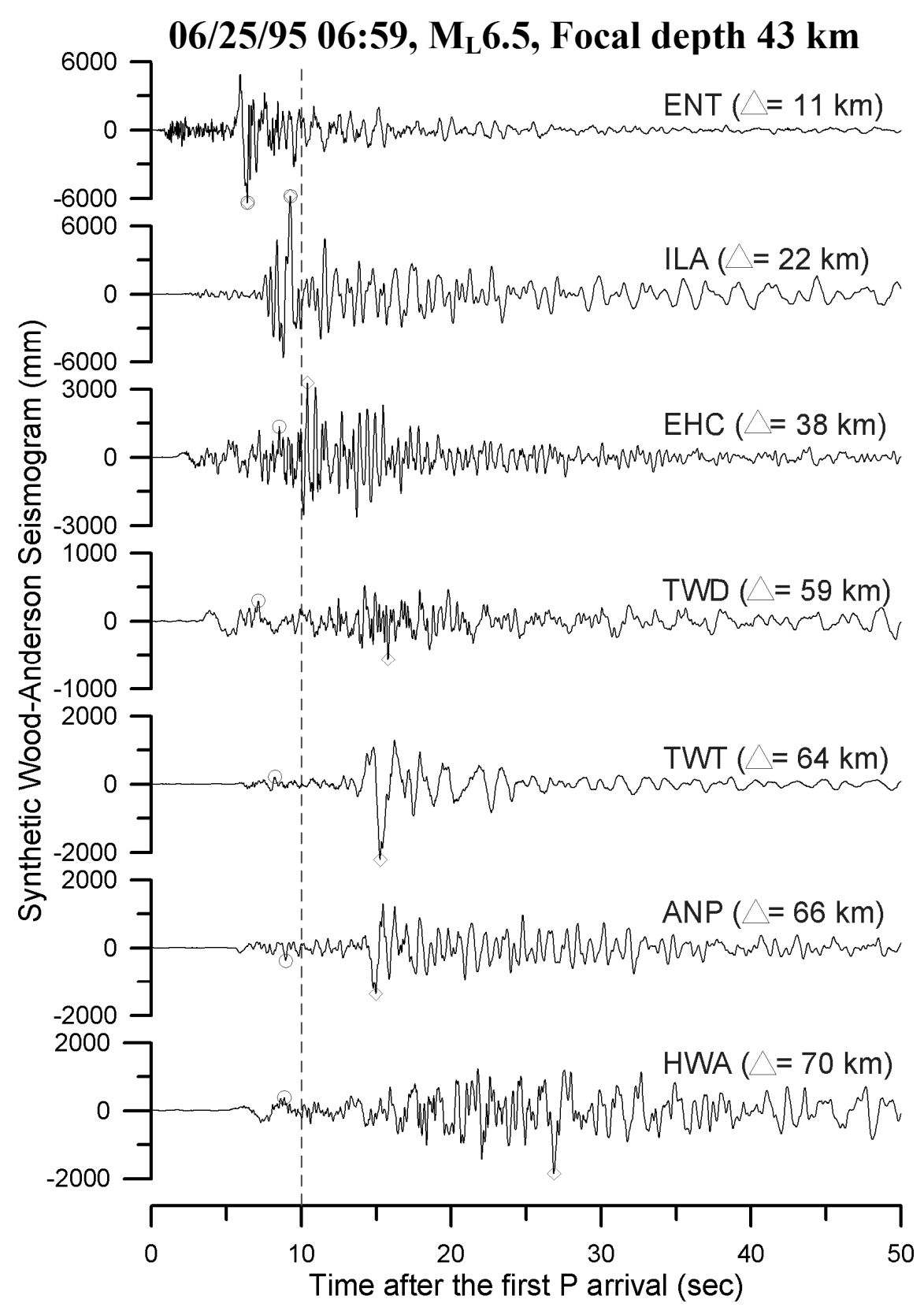

Fig. 14.2 Simulated Wood-Anderson seismograms showing peak readings in the first $10 \mathrm{sec}$ (open circle) and $50 \mathrm{sec}$ (open diamond) after the arrival of the P-wave at the nearest station. 


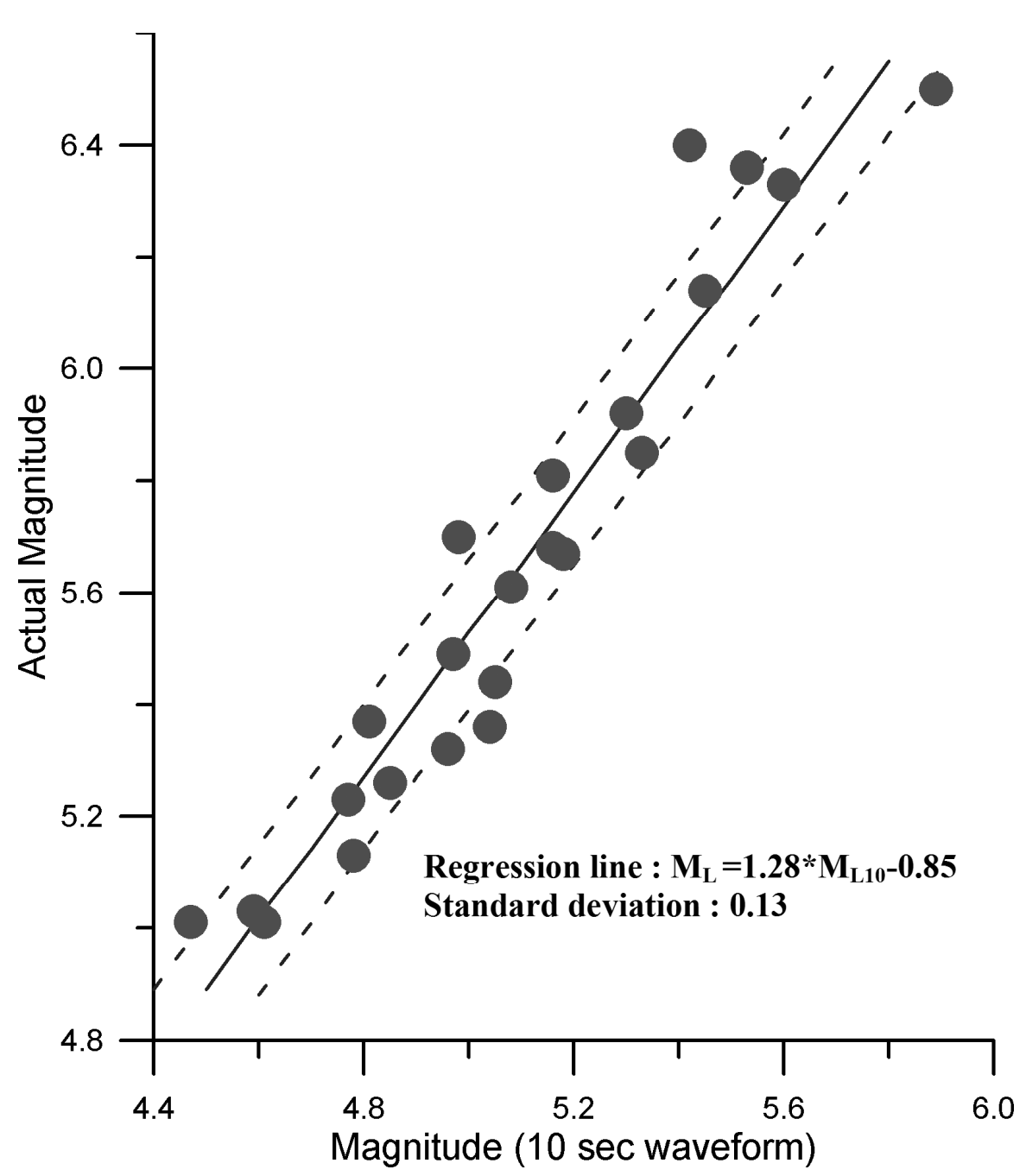

Fig. 14.3 Correlation between the actual $M_{L}$ and tentative $M_{L 10}$ using the first 10sec signals on an accelerogram after the arrival of the $\mathrm{P}$-wave at the nearest station. 


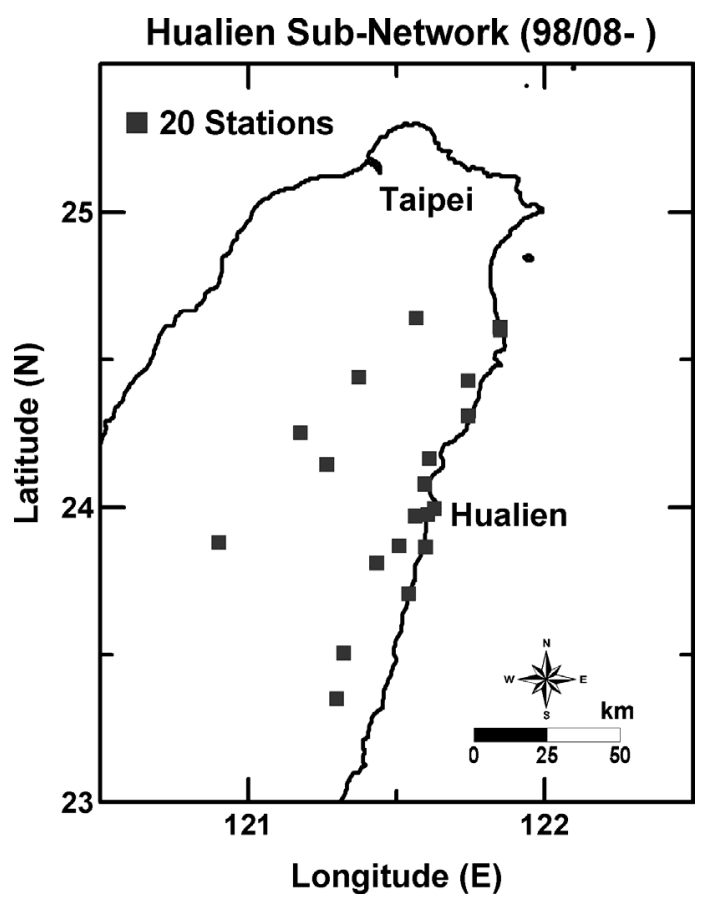

Fig. 14.4 Station distribution of the Hualien sub-network.

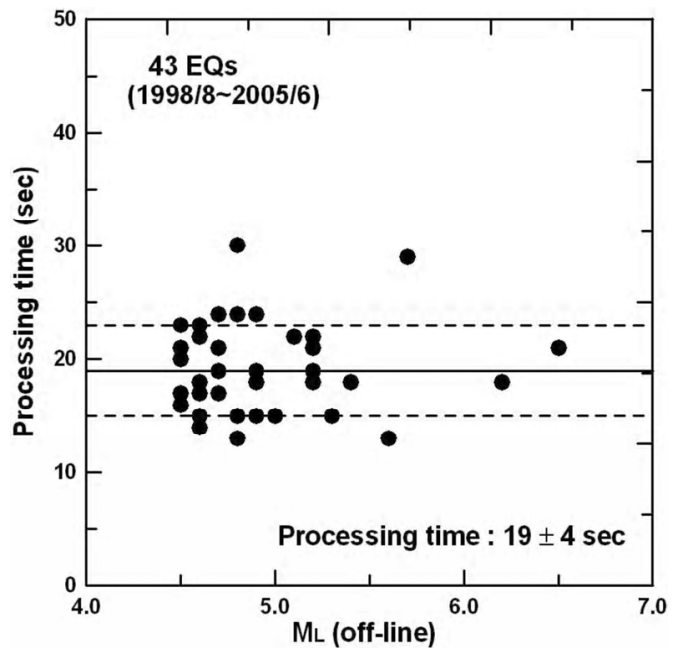

Fig. 14.5 Processing time of 43 events with magnitude larger than 4.5 from 1998 to 2005 being reported by the Hualien sub-network system. 


\subsubsection{Virtual Sub-Network (VSN) Approach}

In the above experiment in Hualien, Taiwan, we demonstrated that earthquake reporting time can be significantly shortened by using a smaller network (Wu et al. 1997, 1999). This leads to the design and configuration of a VSN within the hardware system of the ongoing RTD network. The VSN, automatically configured by the monitoring system, is eventdependent and its configuration varies with time. By working with the VSN, we can substantially reduce the reporting time such that an effective earthquake early warning capability is feasible to cover the entire Taiwan region.

In hypocenter and magnitude determinations, only stations close to the epicenter (less than $60 \mathrm{~km}$ away) contribute the crucial information. Within the framework of the RTD network, we chose to process only signals from a subset of the RTD stations that form a VSN network surrounding an event. As soon as the RTD is triggered by an event, the system automatically extracts a subset of the RTD input signal channels and configures a VSN with a $60-\mathrm{km}$ radius centered on that event. Figure 14.6 also gives a number of possible VSN configurations; each normally consists of about a dozen stations. The extracted data stream for this event forms the basic VSN input data for the subsequent EWS work.

Signals of all stations within a $60-\mathrm{km}$ radius are grouped and extracted through a Multi-IO-Board to form the VSN input, which will then be processed in parallel through the VSN software in a dedicated computer. We conducted a series of experiments to determine the optimum recording time for a $60-\mathrm{km}$ radius network. Our results show that $10 \mathrm{sec}$ is about the optimum. As soon as the 10 -sec waveforms are presented at the VSN system, they will be immediately processed to give simulated WoodAnderson seismograms for magnitude determinations that, in turn, will generate an equivalent moment magnitude. Further reduction of this recording time will cause a significant reduction in the reliability and stability of the magnitude determinations, since insufficient numbers of large $S$ wave amplitudes are available. An increase in the recording time, on the other hand, will severely cut into earthquake early warning time without significantly improving the magnitude determination. The VSN system is programmed to continue the recording of the waveforms up to $10 \mathrm{sec}$ after the first $\mathrm{P}$-arrival, after which hypocenter and magnitude determinations will be carried out. The results are disseminated automatically to the users. 


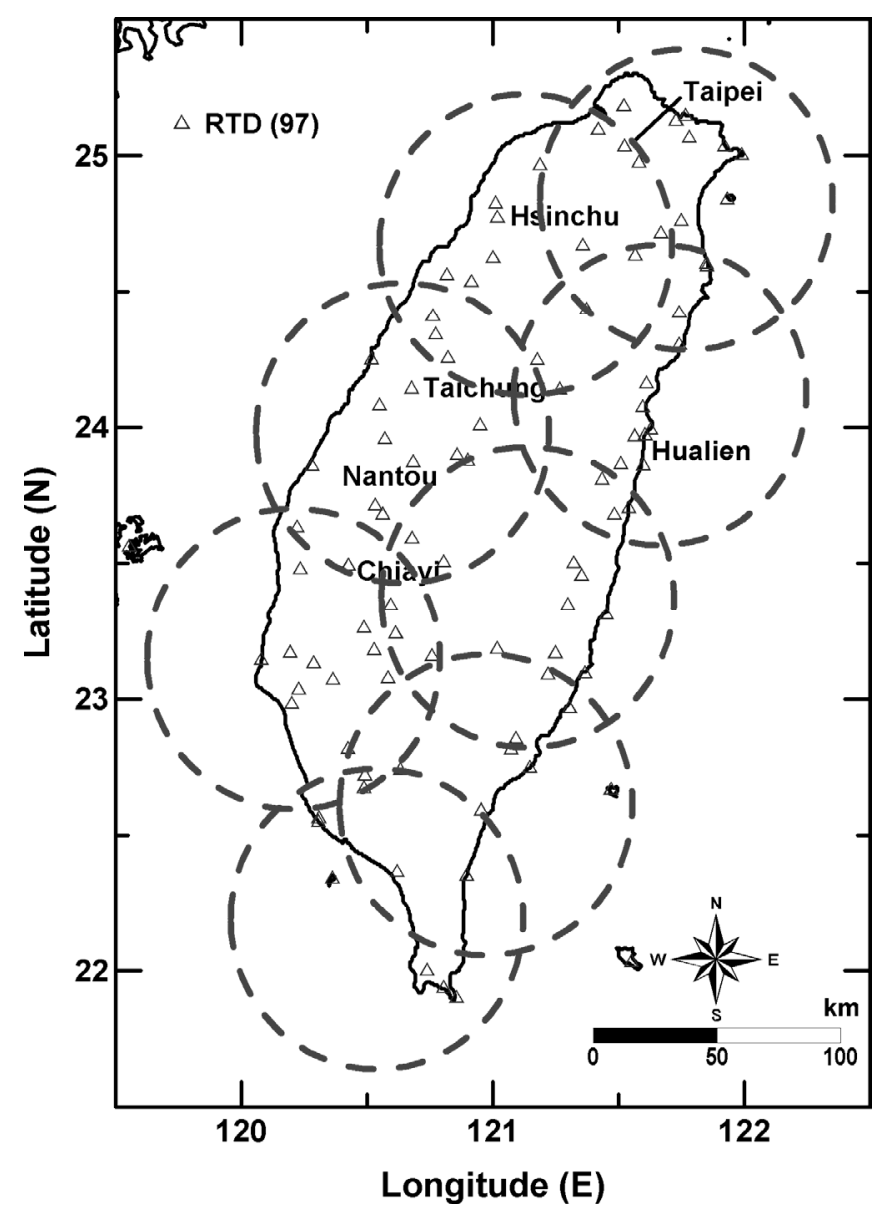

Fig. 14.6 Station distribution of the RTD system and sample VSN networks of 60$\mathrm{km}$ radius configured by software from the RTD system. Each VSN network is centered at a hypothetical event in Taiwan.

We implemented the above VSN operation on the existing RTD network. During the period from December 2000 to June 2005, a total of 125 earthquakes of magnitude $\mathrm{M}_{\mathrm{L}}$ ranging from 4.5 to 6.8 were detected, processed, and reported in real time. If we assume that the off-line manual measurements give the correct values, our VSN results give an average error of $6 \pm 8 \mathrm{~km}$ in epicenter (Fig. 14.7) and an uncertainty of $0 . \pm 0.3$ units in local magnitude. The reporting time is $30 \mathrm{sec}$ or less, with an average of about $22 \mathrm{sec}$. Records of the CWB earthquake early warning system are given in Table 1. 


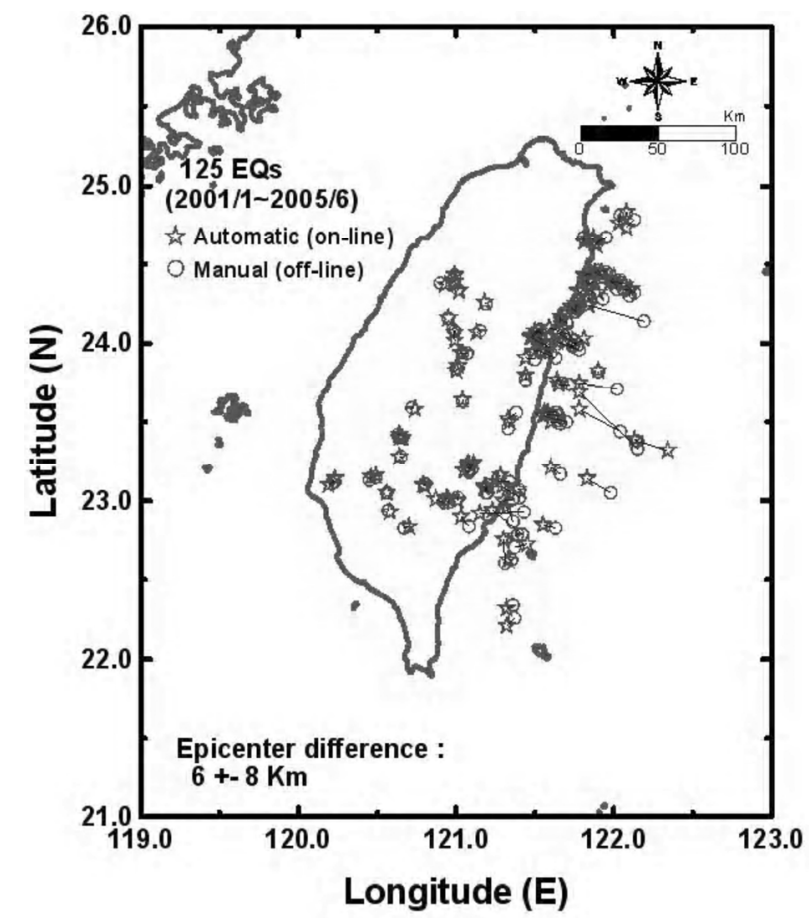

Fig. 14.7 Location differences between the results of the VSN network and those from manual locations.

The Chengkung earthquake $(\mathrm{Mw}=6.8)$ occurred on December 10, 2003 with a focal depth of $10.0 \mathrm{~km}$ reported by the Central Weather Bureau. The main shock occurred at $23.10^{\circ} \mathrm{N}$ and $121.34^{\circ} \mathrm{E}$ along the eastern coast of Taiwan near the town of Chengkung (Fig. 14.8). The EWS of the CWB reported this earthquake information for the same location and magnitude 6.6 at $22 \mathrm{sec}$ after the occurrence. This is a representative case for the CWB early warning system.

For regional warning, the CWB achieved a short earthquake reporting time of about $20 \mathrm{sec}$ (Wu et al. 1998, 1999, Wu and Teng 2002). This can offer earthquake early warning for metropolitan areas located $70 \mathrm{~km}$ from the epicenter and beyond. For an event with the same location as the September 20, 1999 Chi-Chi, Taiwan, earthquake, the Taipei metropolitan area is $145 \mathrm{~km}$ away, and would have more than $20 \mathrm{sec}$ of early warning time. Figure 14.9 shows the expected early warning times for an event like the Chi-Chi earthquake for all parts of Taiwan. The small triangles in Fig. 14.9 give the locations of elementary schools, which essentially reflect the population density. 
14 Yih-Min Wu et al.

Table 14.1 Part of the typical record of the CWB Earthquake Early Warning System.

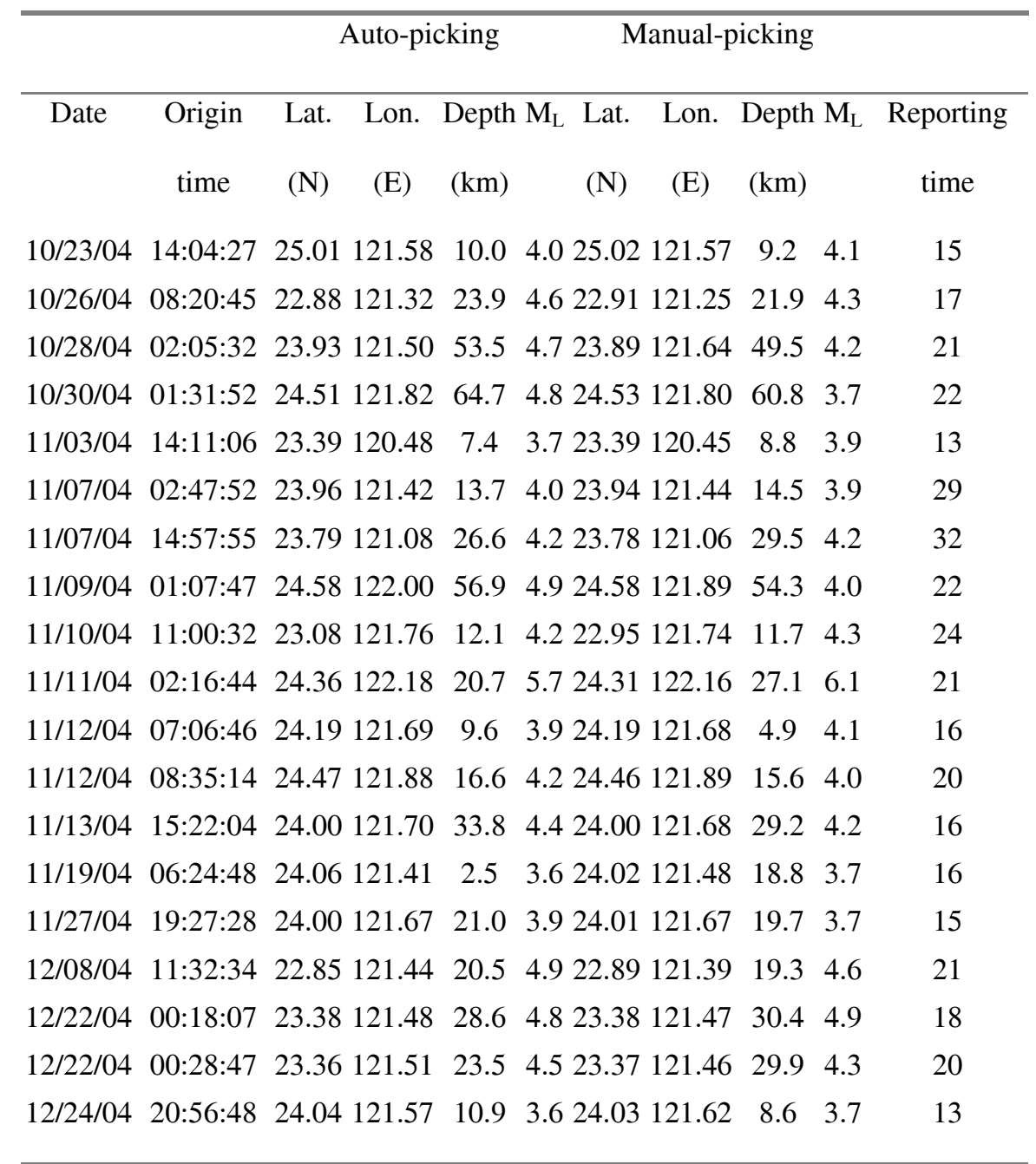




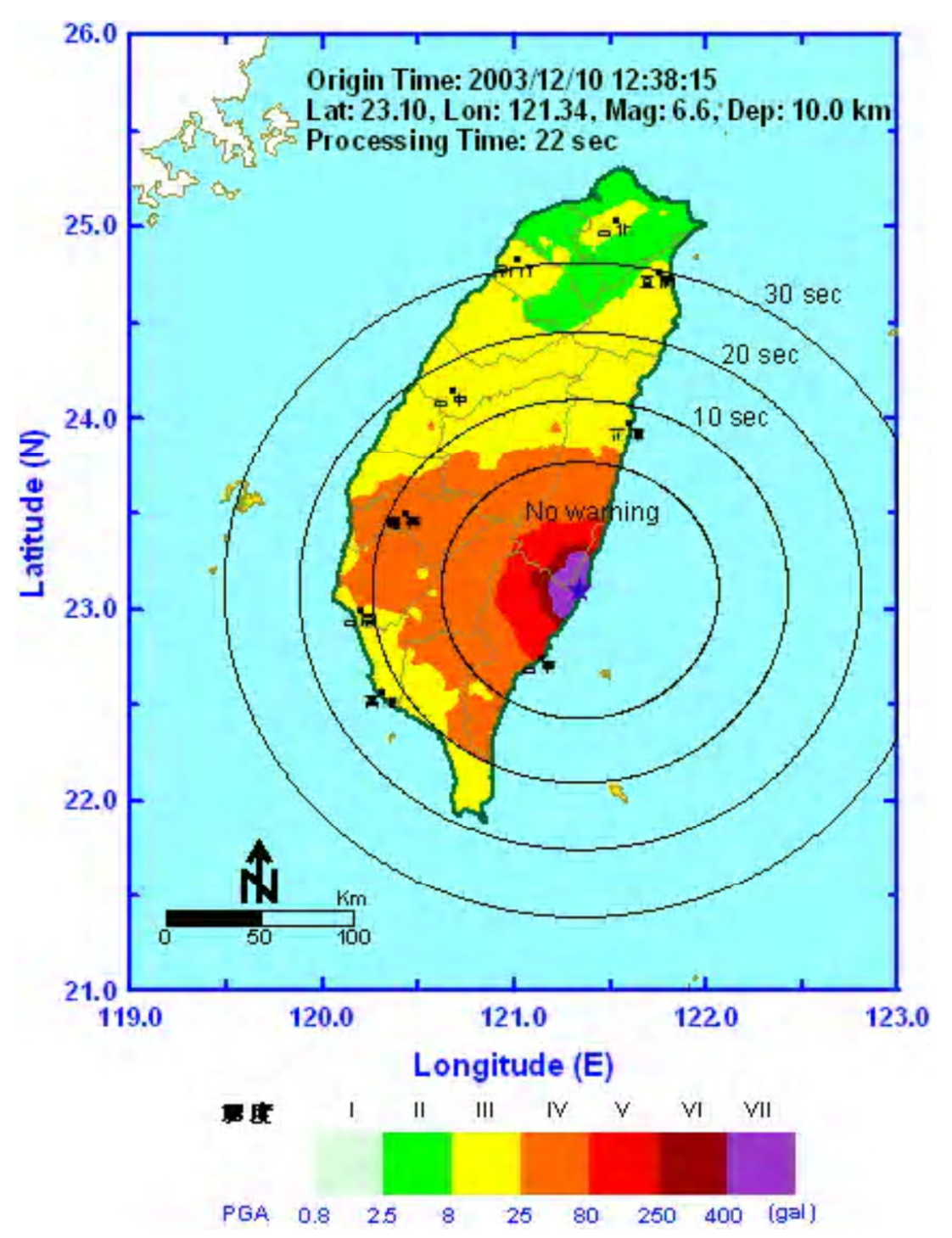

Fig. 14.8 Expected early warning times of the December 10, 2003 Chengkung, Taiwan, earthquake. 


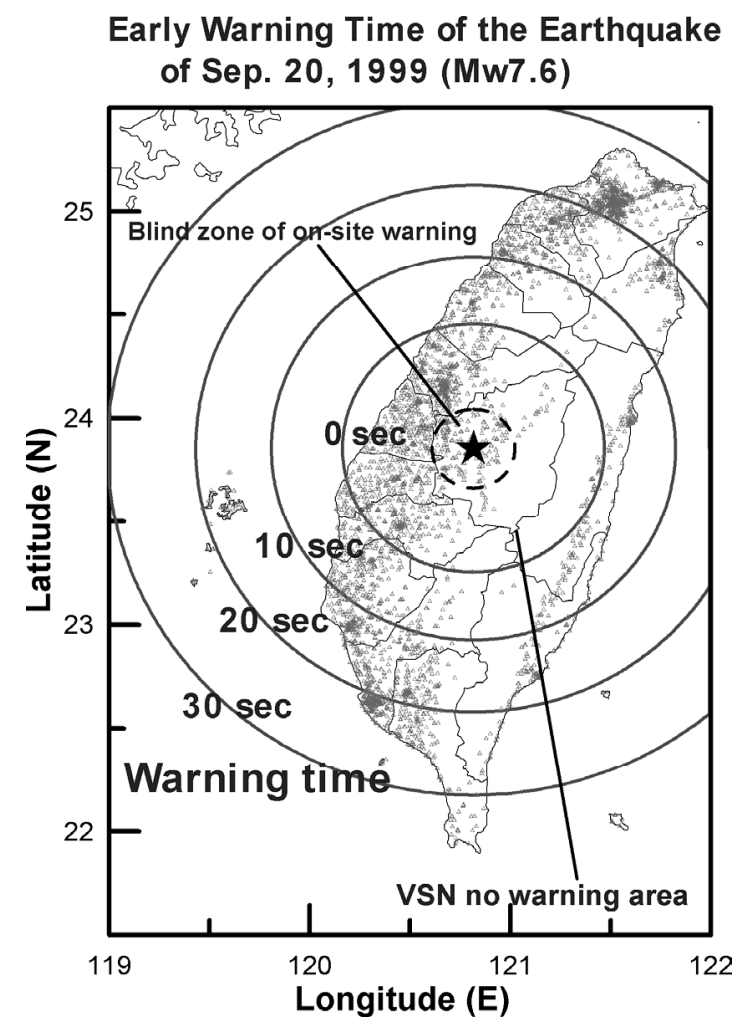

Fig. 14.9 Expected EWS early warning times (indicated by circles) in Taiwan with respect to the occurrence of an event similar to the Chi-Chi earthquake of 20 September 1999. Small circle (dashed) with a radius of $21 \mathrm{~km}$ to indicate the boundary of the blind zone of on-site warning method. Triangles give the location of elementary schools, which can be regarded as the population density of Taiwan.

\subsection{Onsite Warning Methods}

Any earthquake warning system will have a "blind zone" that receives no warning from an earthquake closer than a certain distance. The Taiwan EWS has its "blind zone" defined by a circle with a radius of approximately $70 \mathrm{~km}$. To provide early warning to areas close to the source, a complementary use of an on-site EWS is desirable. Recently, Kanamori (2005) extended the method of Nakamura (1988) and Allen and Kanamori (2003) to determine a parameter, called $\tau_{c}$, that reflects the size of an 
earthquake from the initial $3 \mathrm{sec}$ of the P-waves. Results of $\mathrm{Wu}$ and Kanamori (2005b) showed that Pd (the peak amplitude of displacement during the first $3 \mathrm{sec}$ of P-waves) correlates well with the peak groundmotion velocity (PGV) at the same location. By using the Pd information, we can predict the expected shaking intensity for earthquake early warning purposes. We explored the use of $\tau_{c}$ and Pd methods to complement the front-detection Taiwan EWS system.

A total of 208 strong-motion records from $26 \mathrm{M}_{\mathrm{W}}>5.0$ events in Taiwan are used for this study. The selection criteria are: $M_{w}>5.0$ and focal depth $<35 \mathrm{~km}$ listed in the Harvard CMT catalog (http://www.seismology.harvard.edu/CMTsearch.html). All the events were well recorded by the Taiwan Strong-Motion Instrumentation Program (TSMIP) Network (Fig. 14.1). These events occurred during the period from 1993 to 2003 and were widely felt in Taiwan.

The vertical-component records of the closest eight stations within the epicentral distance of less than $30 \mathrm{~km}$ are used. The acceleration signals are integrated to velocity and displacement. We apply a $0.075 \mathrm{~Hz}$ highpass recursive Butterworth filter to remove the low frequency drift after the last integration. Figure 14.10 shows the relation between PGV and Pd for the data set. The solid symbols indicate the average for each event. For the average values, we obtain a regression relation:

$$
\log (\mathrm{PGV})=0.832 \log (\mathrm{Pd})+1.481
$$

where $\mathrm{PGV}$ is in $\mathrm{cm} / \mathrm{sec}$ and $\mathrm{Pd}$ in $\mathrm{cm}$.

Wu et al. (2003) obtained the following relation between the Taiwan Intensity $\mathrm{I}_{\mathrm{t}}$ and PGV.

$$
\mathrm{I}_{\mathrm{t}}=2.138 \log (\mathrm{PGV})+1.890 .
$$

Combining Eq. 14.2 and Eq. 14.3, we can estimate $\mathrm{I}_{\mathrm{t}}$ from $\mathrm{Pd}$ as

$$
I_{t}=1.779 \log (P d)+5.056
$$

where Pd in $\mathrm{cm}$.

The parameter $\tau_{c}$ is determined by

$$
\tau_{c}=2 \pi / \sqrt{r}
$$

where

$$
r=\left[\int_{0}^{\tau_{0}} \imath \&(t) d t\right] /\left[\int_{0}^{\tau_{0}} u^{2}(t) d t\right]
$$


$u(t)$ is the ground-motion displacement; $\tau_{0}$ is the duration of record used, usually $3 \mathrm{sec}$, and $\tau_{c}$ can be computed from the incoming data sequentially. $\tau_{c}$ reflects the size of an earthquake and in principle is independent of the distance at least to the first order. Figure 14.11 shows $\tau_{c}$ for all events (open symbols) and the average $\tau_{c}$ (solid symbols) as a function of $\mathrm{Mw}$. The $\tau_{c}$ values generally increase with $\mathrm{Mw}$ and are useful for magnitude determinations (Kanamori 2005).

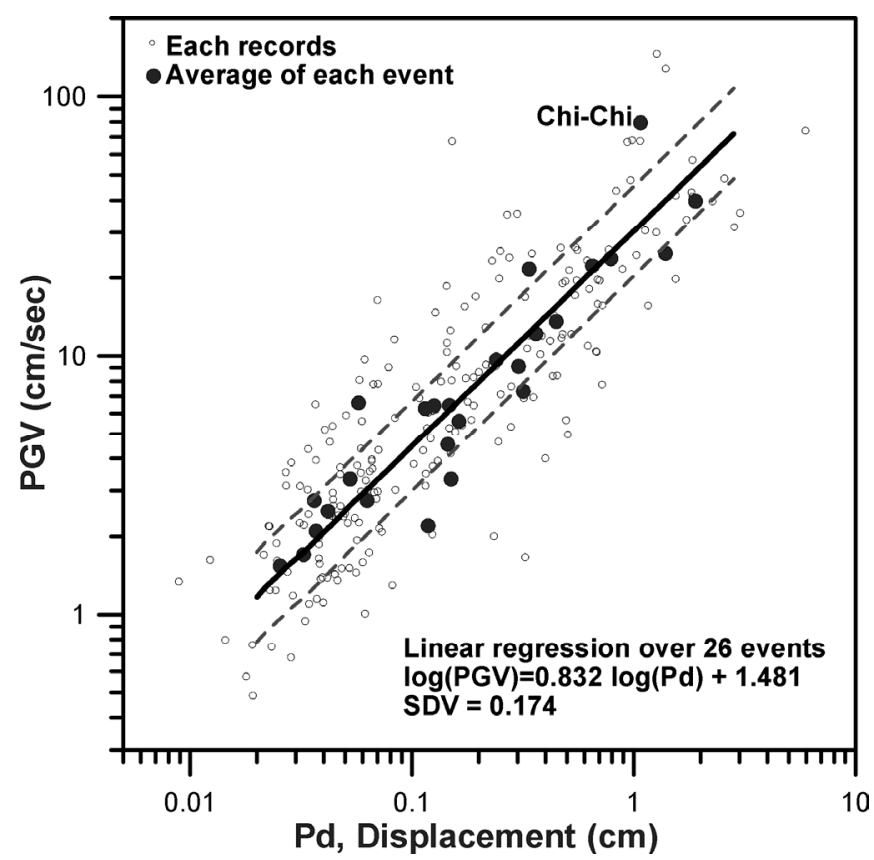

Fig. 14.10 Relationship between peak initial displacement amplitude (Pd) measurements and peak ground velocity (PGV) for the twenty-six events. Solid line shows the least square fit and two dashed lines show the range of one standard deviation. 


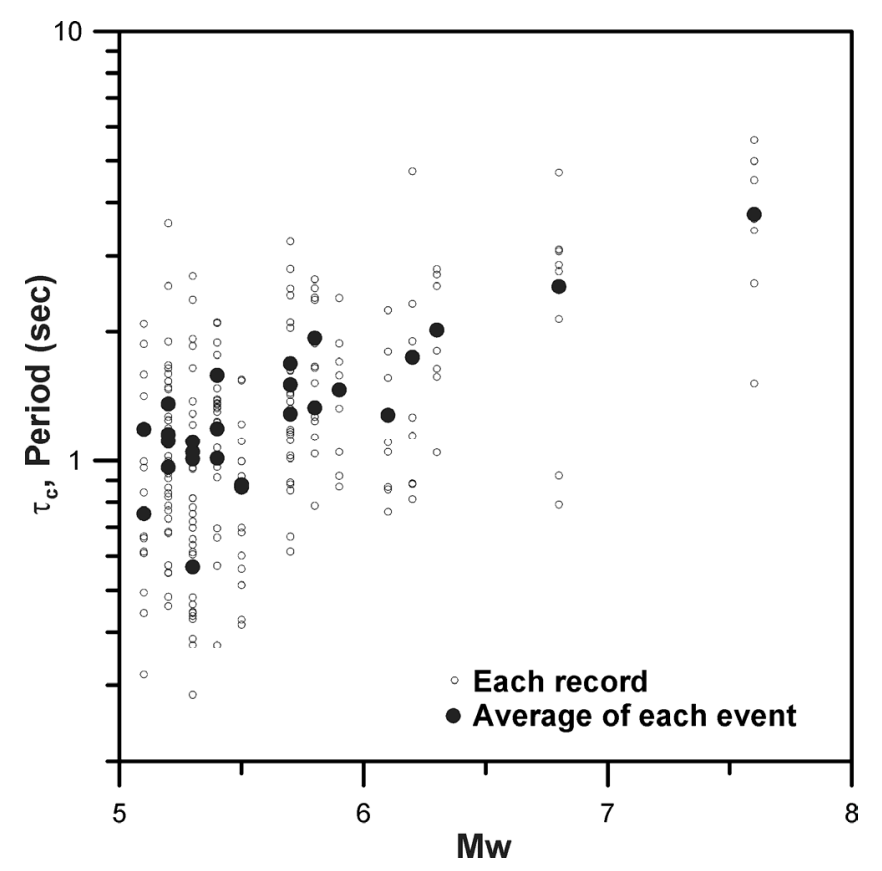

Fig. 14.11 Relationship between period parameter $\left(\tau_{c}\right)$ for the twenty-six events and moment magnitude (Mw).

Although $\log \tau_{c}$ increases approximately linearly with magnitude, the scatter is large for events with $M<5.5$. The large scatter is primarily due to the low signal-to-noise $(S / N)$ ratio when the amplitude during the first 3 $\mathrm{sec}$ is very small. Thus, we removed all the data with $\mathrm{Pd}<0.1 \mathrm{~cm}$ and used only the first 8 stations within $\Delta<30 \mathrm{~km}$ to determine $\tau_{c}$. Figure 14.12 shows the results for which the first 8 records with $\mathrm{Pd}>0.1 \mathrm{~cm}$ are used. Determinations were made for the 12 events for which such data are available. The relationship between the average $\tau_{c}$ and $M_{w}$ is given by,

$$
\log \tau_{c}=0.221 M_{w}-1.113
$$

or, conversely,

$$
M_{w}=4.525 \log \tau_{c}+5.036
$$

By using the $\tau_{c}$ and $\mathrm{Pd}$ methods we can estimate the magnitude and shaking intensity from the initial three seconds of the $\mathrm{P}$ waves. 


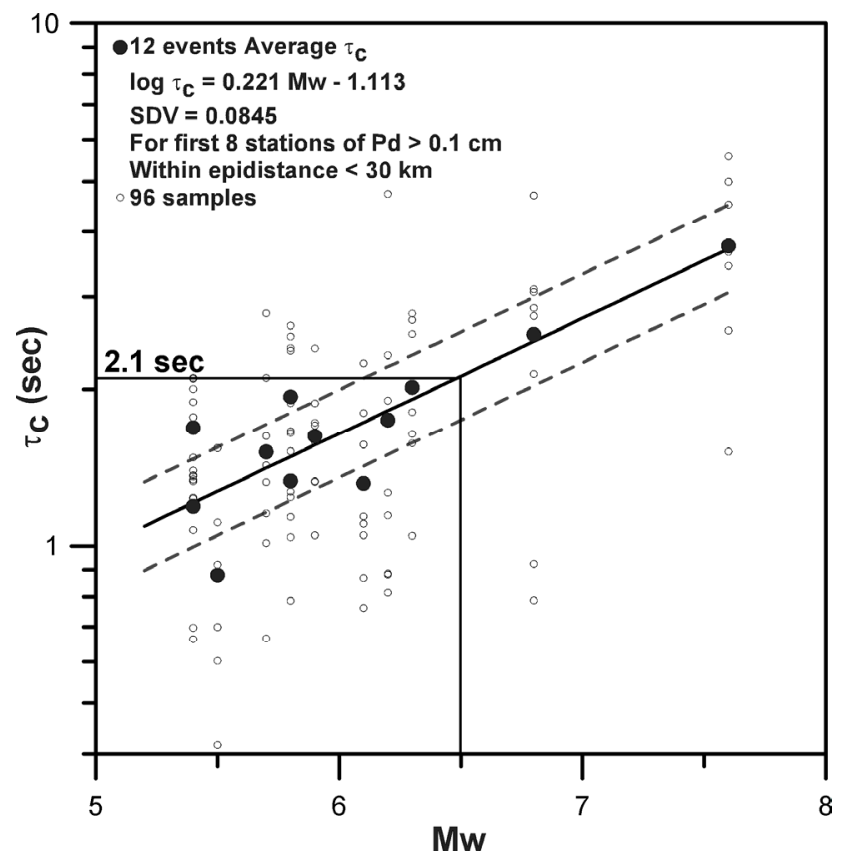

Fig. 14.12 Relationship between the averaged $\tau_{c}$ and $\mathrm{Mw}$ for the twelve events from the closest eight records with $\mathrm{Pd}>0.1 \mathrm{~cm}$.

Figure 14.13 shows the travel time of $\mathrm{P}$ - and $\mathrm{S}$-waves for a reference focal depth at $10 \mathrm{~km}$. Currently the Taiwan EWS can provide rapid reporting at $22 \mathrm{sec}$ after the event origin time by using the VSN method. The current VSN method EWS provides a warning to areas at distances less than about $70 \mathrm{~km}$ from the epicenter (i.e., the radius of the blind zone is $70 \mathrm{~km}$ ). In our experiment on the $\tau_{c}$ method, we used P-waves from the strongmotion records within $30 \mathrm{~km}$ from the epicenter. Figure 14.13 shows that P-waves need about $6 \mathrm{sec}$ to reach $30 \mathrm{~km}$. As this method needs only $3 \mathrm{sec}$ of waveform data, the total procedure needs about $9 \mathrm{sec}$. At that time, Swaves have just propagated to about $25 \mathrm{~km}$ from the epicenter and we can ultimately reduce the radius of the blind zone to $25 \mathrm{~km}$ (Fig. 14.8). 


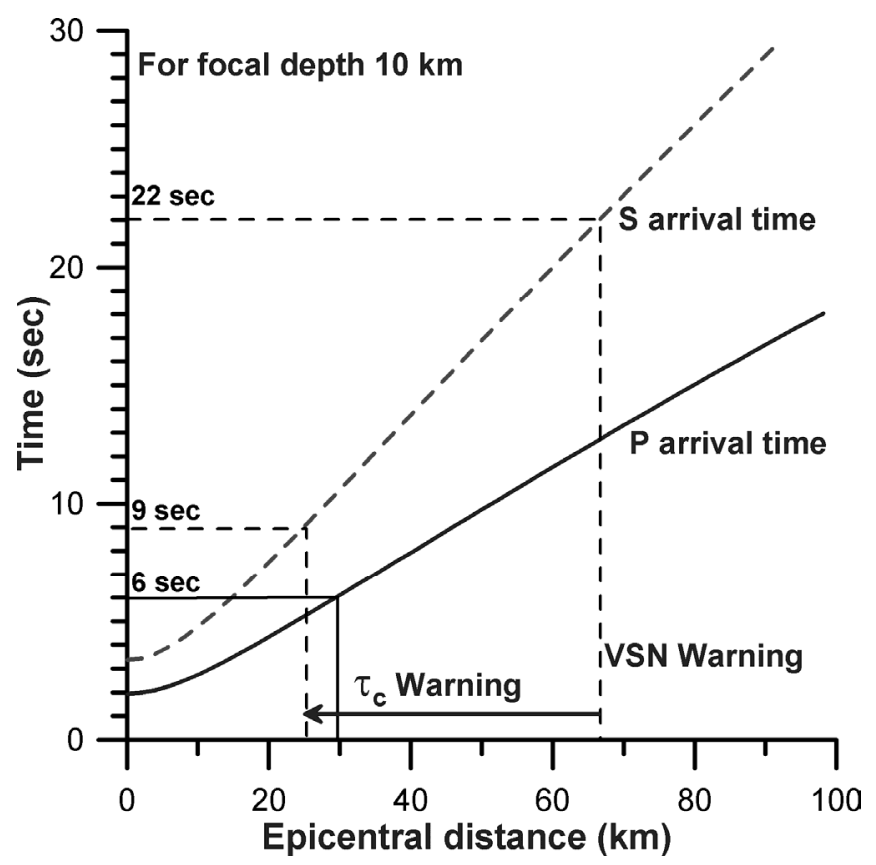

Fig. 14.13 Rapid reporting time and warning distance of $\tau_{c}$ and the VSN methods.

\subsection{Prospects}

Currently, EWS of the CWB is a reliable regional earthquake warning system. It can report information at about $20 \mathrm{sec}$ after the occurrence of a large earthquake. In the future, by applying the $\tau_{c}$ and Pd method it is possible to shorten the reporting time to about $10 \mathrm{sec}$ with necessary hardware improvement. The $\tau_{c}$ and Pd method is an onsite warning approach. Since it estimates earthquake parameters from the initial portion of P-waves, large uncertainties in the estimates are inevitable. Thus, a hybrid of both onsite and regional warning approaches should be built into a future system. Because of the disastrous Sumatra earthquake and tsunami, Lee et al. (2005) proposed a plan to CWB to integrate tsunami warning with earthquake warning. This integration plan is being studied for implementation in the near future. 


\subsection{Acknowledgements}

We wish to thank Prof. Hiroo Kanamori for his stimulating ideas and encouragements. This research was supported by the Central Weather Bureau and the National Science Council of the Republic of China.

\section{References}

Allen R, Kanamori H (2003) The potential for earthquake early warning in South California. Science 300:786-789

Cooper JD (1868) Letter to Editor. San Francisco Daily Evening Bulletin, Nov. 3, 1868

Espinosa-Aranda J, Jiménez A, Ibarrola G, Alcantar F, Aguilar A, Inostroza M, Maldonado S (1995) Mexico City seismic alert system. Seism Res Lett 66: $42-53$

Grecksch G, Kumpel HJ (1997) Statistical analysis of strong-motion accelerogram and it application to earthquake early-warning systems. Geophys J Int 129:113-123

Heaton TH (1985) A model for a seismic computerized alert network. Science 228:987-990

Hsiao NC, Lee WHK, Shin TC, Teng TL, Wu YM (2005) Earthquake rapid reporting and early warning systems at CWB in Taiwan. Poster presentation, Earthquake Early Warning System Workshop, July 13-15, 2005 at the California Institute of Technology, Pasadena, California (website address: http://www.seismolab.caltech.edu/early.html)

Hsu M T (2003) Seismological observation and service in Taiwan (up to 1970). In: Lee WHK, Kanamori H, Jennings PC, Kisslinger C (eds) International Handbook of Earthquake and Engineering Seismology, Part B, CD\#2179_15China(Taipei)।Tai70Hist.pdf, Academic Press, Amsterdam

Kanamori H (2003) Earthquake prediction: an overview. In: Lee WHK, Kanamori $\mathrm{H}$, Jennings PC, Kisslinger C (eds) International Handbook of Earthquake and Engineering Seismology, Part B, pp 1205-1216, Academic Press, Amsterdam

Kanamori H (2005) Real-time seismology and earthquake damage mitigation. Annual Review of Earth and Planetary Sciences 33:5.1-5.20, doi: 10.1146

Kanamori H, Hauksson E, Heaton T (1997) Real-time seismology and earthquake hazard mitigation. Nature 390:461-464

Lee WHK (1995) A project implementation plan for an advanced earthquake monitoring system. Research Report of the Central Weather Bureau, Taipei, Taiwan, R.O.C., No. 448, 411 pp

Lee WHK, Espinosa-Aranda JM (2003). Earthquake early warning systems: Current status and perspectives. In: Zschau J, Kuppers AN (eds) Early Warning Systems for Natural Disaster Reduction, pp 409-423, Springer, Berlin 
Lee WHK, Ma KF, Teng TL, Wu YM (2005) A proposed plan for integrating earthquake and tsunami warning at CWB in Taiwan. Poster presentation, Earthquake Early Warning System Workshop, July 13-15, 2005 at the California Institute of Technology, Pasadena, California (website address: http://www.seismolab.caltech.edu/early.html)

Lee WHK, Shin TC, Teng TL (1996) Design and implementation of earthquake early warning systems in Taiwan. Proc. $11^{\text {th }}$ World Conf. Earthq. Eng., Paper No. 2133

Nakamura Y (1988) On the urgent earthquake detection and alarm system (UrEDAS). Proc. of the $9^{\text {th }}$ world conference on earthquake engineering, TokyoKyoto, Japan

Shin TC, Teng TL (2001) An overview of the 1999 Chi-Chi, Taiwan, earthquake. Bull Seism Soc Am 91:895-913

Teng TL, Tsai YB, Lee WHK (2001) Preface to the 1999 Chi-Chi, Taiwan, Earthquake Dedicated Issue. Bull Seism Soc Am 91:893-894

Teng TL, Wu YM, Shin TC, Lee WHK, Tsai YB, Liu CC, Hsiao NC (2005) Development of earthquake rapid reporting and early warning systems in Taiwan. Oral presentation, Earthquake Early Warning System Workshop, July 13-15, 2005 at the California Institute of Technology, Pasadena, California (website address: http://www.seismolab.caltech.edu/early.html)

Teng TL, Wu YM, Shin TC, Tsai YB, Lee WHK (1997) One minute after: strongmotion map, effective epicenter, and effective magnitude. Bull Seism Soc Am 87:1209-1219

United States Geological Survey (1998) A plan for implementing a real-time seismic hazard warning system - A report to congress required by public law 105-47. March 27, 1998, USA

Wu YM, Kanamori H (2005a) Rapid assessment of damaging potential of earthquakes in Taiwan from the beginning of $\mathrm{P}$ Waves. Bull Seism Soc Am 95:1181-1185

Wu YM, Kanamori H (2005b) Experiment on an onsite early warning method for the Taiwan early warning system. Bull Seism Soc Am 95:347-353

Wu YM, Teng TL (2002) A virtual sub-network approach to earthquake early warning. Bull Seism Soc Am 92:2008-2018

Wu YM, Zhao L (2006) Magnitude estimation using the first three seconds Pwave amplitude in earthquake early warning. Geophys Res Lett 33:L16312

Wu YM, Chen CC, Shin TC, Tsai YB, Lee WHK, Teng TL (1997) Taiwan Rapid Earthquake Information Release System. Seism Res Lett 68:931-943

Wu YM, Shin TC, Tsai YB (1998) Quick and reliable determination of magnitude for seismic early warning. Bull Seism Soc Am 88:1254-1259

Wu YM, Chung JK, Shin TC, Hsiao NC, Tsai YB, Lee WHK, Teng TL (1999) Development of an integrated seismic early warning system in Taiwan - case for the Hualien area earthquakes. TAO 10:719-736

Wu YM, Hsiao NC, Teng TL, Shin TC (2002) Near real-time seismic damage assessment of the rapid reporting system. TAO 13;313-324 
Wu YM, Teng TL, Shin TC, Hsiao NC (2003) Relationship between peak ground acceleration, peak ground velocity, and intensity in Taiwan. Bull Seism Soc Am 93:386-396

Wu YM, Kanamori H, Allen RM, Hauksson E (2006a) Experiment using the $\tau_{\mathrm{c}}$ and $\mathrm{P}_{\mathrm{d}}$ method for earthquake early warning in Southern California. Submitted to Geophysical Journal International

Wu YM, Yen HY, Zhao L, Huang BS, Liang WT (2006b) Magnitude determination using initial P waves: A single-station approach. Geophys Res Lett 33:L05306

Yu SB, Kuo LC, Punongbayan RS, Ramos EG (1999) GPS observation of crustal deformation in the Taiwan-Luzon region. Geophys Res Lett 26:923-926

Zschau J, Kuppers AN (eds) (2003) Early Warning Systems for Natural Disaster Reduction. Springer, Berlin, 834 pp 